\title{
The language assessment literacy needs of Iranian EFL teachers with a focus on reformed assessment policies
}

\author{
Tahereh Firoozi ${ }^{1,3^{*}}$ (D, Kioumars Razavipour ${ }^{1}$ and Alireza Ahmadi ${ }^{2}$
}

\author{
* Correspondence: \\ t-firoozi@phdstu.scu.ac.ir; Firoozi. \\ chamran@gmail.com \\ ${ }^{1}$ Shahid Chamran University of \\ Ahvaz, Ahvaz, Iran \\ ${ }^{3}$ Queen's University, Kingston, \\ Canada \\ Full list of author information is \\ available at the end of the article
}

\begin{abstract}
Teachers' assessment literacy has recently captured the attention of scholars across various educational contexts. The literature has it that there is a gap between teachers' assessment practices and national assessment policies. The present study investigated the assessment needs of Iranian EFL teachers in the wake of the new assessment reform, which aims at replacing traditional discrete point testing policies with performance testing. In-depth interviews were conducted with $15 \mathrm{EFL}$ head teachers. In addition, documents related to the curriculum reform were also closely examined. Inductive coding of the data showed that to meet the demands of the noted reform, teachers' current perceptions of language assessment need to change. Furthermore, teachers need training in both knowledge and skills of language assessment. More specifically, teachers need training in developing rubrics for use in assessing the productive skills of speaking and writing. They also need to develop literacy in devising higher-order thinking skills in assessing reading and listening comprehension. Finally, as non-native speakers of English, Iranian English teachers need better English aural/oral skills.
\end{abstract}

Keywords: Language assessment literacy, Assessment policy, Assessment needs, performance assessment

\section{Introduction}

Language assessment literacy (LAL) is considered a key construct in language assessment literature (Inbar-Lourie 2013). However, what LAL entails for various groups of stakeholders is a subject of debate (Fulcher 2012). Particularly, specifying the components of language assessment literacy for classroom assessment has proven to be a serious challenge (Inbar-Lourie 2008; Rea-Dickins 2008).

Viewed from a sociocultural view of learning, teachers' assessment literacy is taken to be a dynamic process that brings together teachers' assessment knowledge, assessment skills, and their conceptions of assessment in relation to their contexts of practice (DeLuca et al. 2016; Xu \& Brown 2016). The importance of sociocultural context in the conceptualization of teacher's assessment literacy has been echoed in recent studies (Gebril 2016; Scarino 2013). Given that classroom assessment transpires within diverse educational contexts with different educational policies, the identified components of assessment literacy based on the standards of assessment in English speaking

(c) The Author(s). 2019 Open Access This article is distributed under the terms of the Creative Commons Attribution 4.0 International License (http://creativecommons.org/licenses/by/4.0/), which permits unrestricted use, distribution, and reproduction in any medium, provided you give appropriate credit to the original author(s) and the source, provide a link to the Creative Commons license, and indicate if changes were made. 
contexts (e.g., Brookhart 2011; DeLuca et al. 2016; Xu \& Brown 2016) may not be adequate in accounting for the language assessment needs of teachers working in other educational contexts. In the Iranian EFL context, there is evidence that English teachers' language assessment literacy is, at least, partly responsible for teachers' failure to comply with a mandated reform requiring teachers to assess communicative competence rather than discrete bits of language knowledge (Razavipour \& Rezagah 2018). Yet, Razavipour and Rezagah's study was not specifically concerned with the language assessment needs of teachers. Hence, further inquiry into English teachers' language assessment needs in Iran, with its centralized educational system, is warranted. The current study attempts to identify the components of language assessment literacy which are compatible with recent assessment policies of the country.

\section{Teachers' assessment literacy: from measurement to sociocultural perspective}

The recent shift from assessment of learning (AOL) (i.e., "use of assessment to determine the extent to which students have achieved intended learning outcome") to assessment for learning (AFL) ("when teachers use assessment evidence to inform their instruction") (Black \& Wiliam 2018, p. 3) has substantially affected the conceptualization of teachers' assessment competencies (Brookhart 2003). Accordingly, the traditional psychometric approach to identifying teachers' assessment competence has given way to new conceptualizations that take account of the situated nature of assessment practice in the complex contexts of classrooms (Brookhart 2011). Hence, informed by sociocultural learning theories, the context of assessment has been integrated in the conceptualization of teachers' assessment literacy including “... teachers' assessment knowledge, conception of assessment, and their responses to the external contexts embedded with actual constraints and affordances in the environment..." (Xu \& Brown 2016, p.157).

Likewise, in the literature of language testing, all the three components of LAL including assessment knowledge, assessment skills, and principles of assessment (Brindley 2001; Davies 2008) are considered essential for different stakeholders. A body of research has investigated LAL for language teachers (e.g., Jin 2010; Razavipour et al. 2011; Vogt \& Tsagari 2014), for high stake test users (e.g., O’Loughlin 2013), for non-practitioners (e.g., Pill \& Harding 2013), for item writers, university administrators, and for professional language testers (e.g., Taylor 2013).

Defined from a sociocultural vantage point, "assessment culture refers to educational evaluation practices that are compatible with current ideologies, social expectations, attitudes and values" (Inbar-Lourie 2008, p. 285). Accordingly, defining the construct of teachers' assessment competency hinges upon the context of assessment practice (Rea-Dickins 2006). The importance of sociocultural context in the conceptualization of teacher's assessment literacy has also been echoed in recent studies (Gebril 2016; Scarino 2013). Adopting a sociocultural stance on educational assessment in Muslim countries, Gebril (2016) concluded that assessment literacy for teachers in Muslim countries needs to be reconceptualized considering the sociocultural aspects of the Muslim world. Other scholars have taken a modularized approach to language assessment literacy, maintaining that the assessment of each language skill requires its own knowledge base and competence (Crusan et al. 2016; Ölmezer-Öztürk \& Aydin 2018). 
LAL in Iran, as a Muslim country with a centralized educational system, has been studied at different levels including teachers' conception of assessment (e.g., Gebril \& Brown 2014) and teachers' knowledge of assessment (e.g., Ahmadi \& Mirshojaee 2016; Razavipour et al. 2011). However, the noted studies seem to have adopted a universal stance towards the construct of teachers' assessment literacy (e.g., Brookhart 2011; Plake et al. 1993).

The study by Zolfaghari and Ahmadi (2016) is perhaps closer to a contextual understanding of language assessment literacy as it was grounded in a local understanding of LAL. This study led authors to identify general and specific components of language assessment literacy. Although their study contributed to the contextual understanding of teachers' assessment literacy, the components were identified exclusively based on teachers' perspectives without taking account of assessment policies. In addition, a recent study has shown that Iranian English teachers' inadequate LAL is one of the factors contributing to the gap between the reform-based assessment policies and teachers' assessment practice (Razavipour \& Rezagah 2018). Yet, what assessment subskills are needed on the part of teachers to do language assessment consistent with recent assessment policies remains to be investigated.

To help narrow the noted lacuna, the current study attempts to investigate the components of Iranian English teachers' assessment literary considering both the reformed-based assessment policies and EFL teachers' assessment needs. The questions guiding this study are:

1. What are the assessment policies and EFL teachers' assessment needs for classroom assessment practices in Iran?

2. What are the components of assessment literacy that can bridge the assessment policies to practice?

The next section, we briefly introduce Iran's educational system with a focus on its recent language curriculum reform.

\section{The educational system in Iran}

Iran is one of the countries in the Middle East with approximately $98 \%$ Muslim population (The World Bank Group 2018). The Islamic revolution in 1979 has radically changed the educational system. Aiming at Islamizing the system, radical curricular changes were affected at all educational levels. The centralized Ministry of education holds sole authority over the system including textbooks, assessment policy, and staff recruitment (Paivandi 2012).

Seemingly dissatisfied with the outcomes of the education system, in 2010 the Ministry of education initiated an educational reform. To foster sustained learning and problem-solving capabilities, several national, macro-level policy documents, such as 'Fundamental Reform Document of Education (FRDE) in the Islamic Republic of Iran' Ministry of Education (2010a) and 'National Curriculum Document (NCD) of Islamic Republic of Iran' Ministry of Education (2010b) were ratified in early 2010 by Iran's Supreme Council of Cultural Revolution. Accordingly, new textbooks were produced to improve students' learning through focusing on higher-order thinking processes. 
Regarding assessment, educational assessment in Iran has traditionally been exam-oriented, the main aim of which is selecting applicants for limited occupational or educational vacancies. At a classroom level, an orientation towards summative assessment is dominant. In secondary schools, achievement tests are usually developed, administered, and scored by the teachers except for the final summative exams at grade 12 (the end of upper secondary school). The cut-off point for all subjects at all levels of the educational system is $50 \%$ of the total score.

\section{English language policy}

In Iran, English has been part of the official curriculum since 1939 (Foroozandeh \& Forouzani 2015; Riazi 2005). In 1979, in the wake of the Islamic revolution, English textbooks were revised based focusing on reading and grammar, with less attention being given to other language skills.

Given that students' level of language proficiency was not improved after 7 years of school teaching, the Ministry of education launched an educational innovation that aimed at changing both teaching methods and textbook contents (Atai \& Mazlum 2013). Previously, grammar and reading were considered core curriculum objectives, while, in the new curriculum, communication and problem-solving skills are to be the main educational objectives. The following quote captures the main tenets of the new English language curriculum.

Teaching a language is about fostering the ability to communicate and to solve communication problems. Students should be able to communicate using all the four language skills to encode and decode messages. Lessons must planned to enable students put their language knowledge to communicative use. Teaching foreign languages starts from junior high school with the aim of helping citizens successfully engage in international communication through the medium of English (NCD, p.36)

The objectives of the new teaching curriculum are based on Common European Framework of Reference (CEFR) themes and function to help learners reach the A2 level at the end of junior high school and B2 level at the end of senior high school (Foroozandeh \& Forouzani 2015). However, being aware of the "corporate-led globalization" of the spread of English and its resultant cultural and linguistic consequences (Phillipson 2016, p. 81), the Organization for Educational Research and Planning in Iran has made a conscious effort to adapt the textbooks into a localized version of CLT that takes account of Islamic ideology, local values, and the country's local culture.

Assessment mandates in the new curriculum reflect the objectives of the communicative approach. Final assessments of students' learning is based on paper-and-pencil tests of reading and writing (12 out of 20 marks), speaking ( 4 out of 20 marks), and listening (4 out of 20 marks).

\section{Methods}

This study adopted a qualitative approach to investigate the essential elements of assessment literacy for Iranian EFL secondary school teachers in light of the recent English curriculum briefly described above. 


\section{Participants}

The participants of this study were 15 EFL head teachers from Fars and Khuzestan provinces in the South of Iran. Head teachers are selected by the educational dean of the Ministry of education in each province. Being active teachers themselves, head teachers supervise other in-service teachers. They form a network for efficient communications between practicing teachers and the Ministry of Education in Tehran and echo teachers' needs, problems, and progress to the Ministry of Education. The number of head teachers in each province depends on the number of districts in each province. In this study, head teachers were selected for three reasons: (a) they were considered the most informed teachers regarding the new curriculum since they had been involved in the curricular reform from its very inception through a variety of workshops, (b) head teachers are usually experienced teachers with senior curricular status, and (c) they are in constant contact with other teachers and are current with their needs, problems, and concerns. For the noted reasons, the head teachers were considered 'key informants' (Patton 2014) who had the necessary knowledge and experience to supply relevant information about the phenomenon under investigation in this study.

\section{Data collection}

Data collection was conducted from April 2017 to June 2017. Official letters were handed to the research departments of provincial Offices of Education in Fars and Khuzestan to gain permission for interviews with head teachers. After obtaining official permission, we contacted the head teachers in each province. All the head teachers (four teachers) of the four District Educational Offices in Shiraz (the capital of Fars Province) and three of the head teachers from other cities (Darab, Kazerun, and Marvdasht) in Fars agreed to participate. In Khuzestan province, five head teachers from among the four District Educational Offices in Ahvaz (the capital of Khuzestan), and three head teachers in other cities (Khoramshahr, Dezful, and Shoushtar) agreed to an interview session. The head teachers who agreed to interview sessions were asked to sign ethical consent forms.

To understand teachers' perspectives and needs in classroom assessment, data collection was conducted through semi-structured, audiotaped interviews. Each interview lasted approximately $60 \mathrm{~min}$. Interview questions focused on (a) the participants' perceptions of the assessment policy expectations for classroom teachers and (b) teachers' assessment needs to assess English language skills in sync with new curricular objectives. The audiotaped interviews were transcribed verbatim by the interviewer after each interview session.

In addition, national macro-level policy documents (i.e., FRDE and NCD) as well as the available interpretation of the grand documents in the official website of the Ministry of Education were collected.

\section{Data analysis}

To derive the codes and themes in the data, we allowed the themes to be suggested by the data while we were having an eye on the policy documents too. Drawing on iterative collaborative analysis process (Hall et al. 2005), the first author examined the interview transcriptions and documents inductively for codes and themes of close relevance 
to language assessment. Interview transcripts were analyzed through an iterative process involving reading, focused coding, reflection, writing, and rereading to make connections between codes. Codes with a high degree of shared construct were reframed into broader themes.

Significant codes and codes that had logical coherence with rich supported examples were categorized into themes. To ensure inter-coder reliability, the induced codes, themes, definition of the themes, and examples were discussed by the authors. Through discussion and negotiation, some changes were made to the initial derived codes. Salient among such changes were the reduction of themes from three in the original coding to two themes after negotiation. As such, assessment knowledge and assessment perceptions were merged into one single theme of language assessment literacy. Finally, the emergent codes of the interview analysis were categorized into two themes: reformed-based assessment support and teachers' assessment literacy.

\section{Results}

In this section, findings pertinent to each data set (i.e. documents and interviews) are presented respectively.

\section{Assessment policies}

Reviewing the grand documents relevant to educational assessment in k-12 and documents relevant to English language curriculum reform, we identified 42 assessment-relevant standards. The standards were categorized into three major themes as (a) type of assessment, (b) purpose of assessment, and (c) assessment criteria.

\section{Types of assessment}

Different forms of assessment as diagnostic, progressive, and summative are emphasized in the grand documents. Accordingly, teachers are encouraged to use alternative forms of assessment in assessing students' learning progress, outcomes, and the quality of instruction. Six out of 42 standards address the type of educational assessment. For example,

5.1.1. Evaluation includes diagnostic assessment, progressive assessment, and summative assessment which can be achieved through paper-and-pencil, oral, performance assessment, self-assessment, peer assessment, and informal observation. Decision about students' progress and the success of instruction are made based on these evaluations. (NCD, p.126)

5.2.5. Self-assessment should be encouraged. (NCD, p. 127)

19-2. Planning and implementation of a product-oriented evaluation system based on the national standards for transitions between different stages of education and a process-oriented assessment system for transitions from one grade into another in primary schools and an eclectic approach (a combination of outcome and process oriented) approach in other levels of education. (FRDE, p. 48)

5.2.1. By using various methods and instruments, teachers can fully reflect the students' ability to use their basic competencies in different domains. (NCD, p.126) 


\section{Purposes of assessment}

In addition to assessment types, the grand documents also address how the information gained form assessment should be used. As such, three the documents indicate that assessment must be used for the following three purposes: assessment for learning, assessment of learning, and assessment as learning.

Assessment for learning takes place when information gained form assessment is used to inform instruction. Seven out of 45 standards of NCD focus on using assessment information to modify instruction. For example,

5.3.3. Assessment is an inseparable part of the learning-teaching process and its results are used for fostering teachers' professional growth and improving lesson plans and the educational system. (NCD, p. 126)

5.4.7. Individual differences in learning should be considered and the results should be used for decision making about instruction. (NCD, p. 130)

5.3.3. In evaluating students' progress, students' learning processes and products of learning should be considered. (NCD, p.128)

Likewise, assessment of learning has been considered in the grand documents with focusing on evaluating students' ability as a product. Five out of 45 standards of assessment highlight strategies and principles of assessment of students' learning. For example,

5.2.9. To assign grades to students' final achievements, an assessment that is outcome oriented must be in place. Such an assessment system must be based on national standards. (NCD, p. 127)

5.4.6. In order to report results of students' learning qualitatively and quantitatively, all the methods of assessment, oral, written, observation, essay, performance, and portfolio should be practiced. (NCD, p. 130)

5.3.3. In evaluating students' progress, students' learning process and product of learning should be considered. (NCD, p.128)

Furthermore, assessment as learning refers to the situation where assessment and learning are considered integrated and assessment is primarily used to scaffold learning (Black \& Wiliam 2018). Seven of the standards of assessment in the grand documents consider assessment as learning. For example,

5.2.4. Given the emphasis of Islam on the knowledge of self and self-assessment, assessment information should help students to diagnose their own strengths and weaknesses. (NCD, p.128)

5.3.7. The information gained from assessment should help students to diagnose their strengths and weaknesses so that students develop a favorable attitude towards lifelong learning. (NCD, p.128)

5.3.11. All the stakeholders should be informed about the process of assessment before its administration. (NCD, p.129)

5.4.8. Assessment should contain feedback which helps learners diagnose their weaknesses and strengths in order to improve their lives through reflection, faith in Allah, ethics, and science. (NCD, p.130) 


\section{Assessment quality criteria}

According to the documents, any kind of assessment should satisfy three quality criteria: appropriateness to students' ability levels, feedback, and psychometric properties. According to the standards, students' ability levels should be taken into consideration through including items targeting various cognitive processes such as understanding, application, analyzing, evaluation, and creativity. In addition, quality assessments should provide feedback to improve students' learning. The third quality assessment criterion is the psychometric properties of tests, which can be met through examining validity and reliability. Standards which refer to the quality of assessment are:

5.2.13. The process of assessment should be valid and reliable. (NCD, p.127)

5.4.5. With an emphasis on cooperative activities and problem-solving methods, competition must be discouraged and the grounds for students' growth and development must be established. (NCD, p.130)

\section{Teachers' assessment needs}

Generally, the majority of head teachers believed that although the focus of the reformed curriculum is on listening and speaking, the nature of teachers' classroom assessment practices has not remarkably changed from the previous grammar translation method (GTM). With regard to teachers' assessment needs to implement classroom assessment practices with focusing on the reformed objectives, two themes emerged from the data: (a) reform-based assessment support and (b) teachers' assessment literacy. Table 1 summarizes themes with definitions, codes, and examples.

\section{Reform-based assessment support}

Reform-based assessment support refers to the resources that teachers need to practice classroom assessments compatible with the curriculum reform. As the participants noted, for English teachers to do assessments consistent with the reform, two conditions must be met: transparency of assessment criteria and provision of the right infrastructure.

Table 1 Themes, definitions, codes, and examples

\begin{tabular}{|c|c|c|c|}
\hline Themes & Definitions & Codes & Examples \\
\hline $\begin{array}{l}\text { Reformed- } \\
\text { based } \\
\text { assessment } \\
\text { support }\end{array}$ & $\begin{array}{l}\text { Facilities which teachers } \\
\text { should be provided with } \\
\text { in order to practice the } \\
\text { reform-based assessment }\end{array}$ & $\begin{array}{l}\text { Assessment guideline, } \\
\text { infrastructure }\end{array}$ & $\begin{array}{l}\text { Head teacher 8: The problem is } \\
\text { that in our Grand Documents, the } \\
\text { policy is not mentioned in detail } \\
\text { and just the general grading } \\
\text { issues (Barombandi) have been } \\
\text { mentioned. } \\
\text { Head teacher 2: Since the class } \\
\text { size is large, all the students } \\
\text { cannot participate in the } \\
\text { activities each session. }\end{array}$ \\
\hline $\begin{array}{l}\text { Teachers' } \\
\text { assessment } \\
\text { literacy }\end{array}$ & $\begin{array}{l}\text { Teachers' assessment knowledge } \\
\text { and perception and their ability } \\
\text { to practice their knowledge in } \\
\text { educational contexts. }\end{array}$ & $\begin{array}{l}\text { Teachers' assessment } \\
\text { knowledge, teachers' } \\
\text { assessment perceptions }\end{array}$ & $\begin{array}{l}\text { Head teacher 3: ...teachers' } \\
\text { perspective and their own way of } \\
\text { teaching has been fixed in their } \\
\text { mind. Change is very hard for } \\
\text { teachers. } \\
\text { Head teacher } 11 \text { : As the textbook } \\
\text { has changed, there is a need for } \\
\text { teachers to enhance their abilities } \\
\text { in listening and speaking. }\end{array}$ \\
\hline
\end{tabular}


The majority (14 out of 15 ) of the head teachers believed that the main reason for unsuccessful implementation of the reform-based assessment is the lack of clear criteria for assessing speaking and listening skills. Although assessing speaking and listening abilities has been emphasized in the new curriculum, teachers are not well-informed about the criteria for grading oral or written performance. For example, head teacher 12 mentioned that "currently, teachers are lost since the Ministry of Education has not provided them with sample items or clear assessment specifications. Teachers have been told what not to do (discrete point testing) but have been left to their own devices regarding what to do".

For English teachers to do performance testing, proper infrastructure was the next code emerged from interview data. According to head teachers, limited audio/visual equipment and large class sizes hamper the implementation of reformed-based assessments. Eleven head teachers believed that schools are not equipped with necessary audio/visual systems to assess students' communication skills. According to head teacher 12 ,

Teachers are supposed to play the listening audios of the textbooks in the classroom. However, $90 \%$ of the schools are not equipped with audio-visual facilities like language laboratories. So we ask students to memorize the dialogues and patterns of their textbooks to be able to use them in the final interview exam.

In addition, all of the head teachers asserted that large class sizes impede alternative assessments such as group work, peer assessment, and individualized feedback. The following quote from head teacher 9 is telling.

Group work has been heavily emphasized in teachers' guide book. However, when I observe teachers, I realize that almost none of the teachers does group work in the class. The reason is that teachers cannot manage the class by conducting group works... Since the classes are overcrowded, teachers cannot monitor all the groups to see whether they are doing the expected task, or they are just chatting irrelevant issues in Farsi. In addition, doing a group work in the large classes encourages low-ability students to pass all the responsibilities to more able students.

Altogether, head teachers believed that lack of transparency of assessment criteria and infrastructure challenges have limited practicing assessment for learning and communication skills, with the need for the Ministry of Education to provide teachers with more equipment and clearer guidelines for assessing aural/oral skills.

\section{Assessment literacy}

Head teachers emphasized that lack of teachers' assessment knowledge and teachers' assessment perspectives are two main factors accounting for poor language assessment practices at schools. From among the components of teachers' assessment knowledge, the head teachers referred to teachers' lack of subject matter knowledge and item writing.

The ability to communicate fluently in English constitutes a core component of subject matter knowledge for English teachers. Almost all the head teachers believed that a 
significant number of English teachers are not fluent in English speaking or listening. The head teachers pointed out that since teachers' English language proficiency is not tested prior to employment, they may lack the ability to express themselves in English. As a result, teachers cannot preach what they themselves do not practice. As head teacher 5 articulated,

If teachers could teach the textbook, it would be interesting and desirable, but the problem is that teachers do not have the required knowledge to do so. They lack adequate English proficiency. Some English teachers were first hired for the service jobs by the Ministry of Education. Then, they got an associate degree, left their service jobs and became teachers. So, they do not have enough knowledge to teach and assess English speaking and listening skills.

Twelve of the head teachers believed that for teachers to conduct proper performance assessments, teacher training courses aimed at improving teachers' speaking and listening skills are essential for teachers. For example, head teacher 6 said: "The speaking and listening abilities of teachers are quite poor, and they have not been adequately trained during their pre-service training programs."

The second major gap in teachers' language assessment literacy, according to interview participants, was item writing. The participants maintained that since most of the classroom assessments are still paper-and-pencil tests, teachers need to know how to craft appropriate test items/tasks. In particular, teachers need training in how to devise test tasks and items that can effectively tap into higher-order thinking skills such as problem solving.

In addition, six of the head teachers pointed out that teachers sometimes write multiple choice items with incorrect stems. Head teacher 8 said "In the new curriculum, teachers are mainly responsible for developing the final English exams; yet, many of them cannot write items in accordance with the new curriculum."

Moreover, the head teachers believed that teachers' perspectives towards assessment affect their classroom assessment practices. Although the focus of assessment has been changed from AOL to AFL at macro-level policy, teachers still have an AOL mindset. The head teachers maintained that without changes in teachers' beliefs about language assessment, expecting changes in assessment practices is not realistic. As head teacher 13 indicated,

The new textbooks are more interesting than before. However, in my opinion, the thing that should change is the perspective of the teachers. This issue needs time for teachers to change their mentality and methods. I think changing the perspective is the prerequisite for changing the method.

Furthermore, although assessment for learning has been emphasized in the grand documents and though teachers have been encouraged to use alternative assessments, such as portfolio, self-assessment, and informal observations, teachers' conceptions of assessment are still preoccupied with paper-and-pencil tests or quizzes. As head teacher 15 mentioned,

The focus of the new textbook is on speaking and listening while teachers' perspectives about teaching and assessment have not changed from GTM and paper-and-pencil tests. One possible reason is that teachers test as they have been tested in their own schooling days. 
In sum, though the new assessment policies seem to be cutting-edge and progressive and seek to promote an assessment for learning culture, in-service English teachers have not been provided with the professional and logistic resources to transition from discrete point testing to more authentic, performance assessments.

\section{Discussion}

This study was an attempt to investigate the components of assessment literacy needed for Iranian EFL teachers to practice the reformed-based polices in the centralized educational system of the Islamic republic of Iran. To this aim, the grand documents pertinent to the reform and interviews with head teachers were analyzed qualitatively. Results indicated that at a policy level, different types of assessment are emphasized and high-quality assessments are promoted. However, in practice, data supports the need for more transparent and practical language assessment guidelines, more language assessment knowledge for teachers, and changes in teachers' assessment perceptions.

Analysis of documents showed that the reformed-based assessment policies in Iran follow the assessment for learning paradigm (Black \& Wiliam 1998). In addition, students, who had no say in their own assessments in the previous curriculum, are now expected to take responsibility for their learning through self-regulation and self-assessments (Razavipour \& Rezagah 2018).

Despite this, teachers' perceptions of language assessment were found to be incompatible with the assessment ideals promoted in the new curriculum. Specifically, although the reformed-based assessment policy emphasizes AFL and alternative forms of assessment, teachers' views of assessment are still exam-oriented. This echoes findings from previous studies in the literature (see Atai \& Mazlum 2013; Razavipour \& Rezagah 2018; Zolfaghari \& Ahmadi 2016). This underlines the crucial role of grassroots movement in educational innovations (Fullan 2012).

Moreover, interviews with head teachers indicated that teachers need training both in the subject matter knowledge and in the pedagogy of assessment. This finding parallels those from earlier studies (e.g., Razavipour \& Rezagah 2018; Zolfaghari \& Ahmadi 2016), suggesting that to assess communicative language skills, teachers need to know how to meaningfully communicate in English as well as how to assess the construct of communicative competence (Morrow 2018). Since the teacher recruitment policy has not changed, the crises of teachers' lack of communication skills still is an issue (Hayati \& Mashhadi 2010).

Consistent with other studies (e.g., Atai \& Mazlum 2013; Brookhart 2013; Mertler 2001; Razavipour \& Rezagah 2018; Stiggins et al. 2006), this study supports the crucial need for clear assessment guidelines in practicing classroom assessment. Despite the importance of assessment guidelines in successful practice of assessment reforms (Berry 2011), the proposed assessment guidelines released by Iran's Ministry of education, known as Barombandi, does not fulfill teachers' need for practicing the policy (Atai \& Mazlum 2013). The gap between assessment policy and practice can be bridged by aligning the policies with the assessment norms and developing teachers' assessment literacy (Carless 2009). Considering the aforementioned assessment policies and teachers' assessment needs, three areas of assessment literacy need special attention: (a) rubric development and use (Brookhart 2013), (b) item writing, (c) subject matter knowledge. Given the aim of the reformed curriculum, for English teachers to test, 
measure, and document students' communicative competence, they themselves need to master high-level English communication skills.

Furthermore, irrespective of the educational context, teachers should have sufficient knowledge of the curriculum, content, and the subject matter they teach in order to do effective assessments (Brookhart 2011; Gudmundsdottir \& Shulman 1987; Xu \& Brown 2016). This suggests that to assess communicative language ability (Bachman 1990), teachers need to know how to meaningfully communicate in English as well as how to assess the construct of communicative competence (Morrow 2018).

\section{Conclusions}

To bridge the gap between new assessment policies in Iran and English teachers' assessment practices, the components of language assessment literacy must first be identified. This can be done more fruitfully using a sociocultural perspective. The current study was a modest effort in this direction. The analysis of documents and interviews revealed a mismatch between policies and practices. To remove or reduce the noted mismatch, teachers' English communication skills must be improved through in-service or pre-service programs. Once this is taken care of, teachers need to be trained in devising and using rubrics to systematically diagnose, measure, and record students' communicative competence in English. The third issue contributing to the noted mismatch between new language assessment policies and teachers' assessment practices is poor item writing skills on the part of teachers. Interviews with head teachers revealed that teachers are not proficient in writing written items that can assess higher-order thinking processes like finding the writer's attitude towards the topic, global understanding of text, skimming, finding main ideas, or telling facts from opinions.

\section{Abbreviations}

AFL: Assessment for learning; AOL: Assessment of learning; CLT: Communicative language teaching; EFL: English as a foreign language; FRDE: Fundamental Reform Document of Education; LAL: Language assessment literacy; NCD: National Curriculum Document

\section{Acknowledgements}

We appreciate the kind cooperation of the head teachers who participated in the interview sessions despite their tight teaching and life schedules.

Availability of data and materials

No, being committed to the code of ethics, we keep the data for this project confidential.

\section{Authors' contributions}

The manuscript was written by the lead author. The second and the third authors provided invaluable feedback on different versions of the manuscript. Part of the data analysis has been conducted at Queen's University, Canada. All authors read and approved the final manuscript.

Competing interests

The authors declare that they have no competing interests.

\section{Publisher's Note}

Springer Nature remains neutral with regard to jurisdictional claims in published maps and institutional affiliations.

Author details

${ }^{1}$ Shahid Chamran University of Ahvaz, Ahvaz, Iran. ${ }^{2}$ Shiraz University, Shiraz, Iran. ${ }^{3}$ Queen's University, Kingston, Canada.

Received: 5 November 2018 Accepted: 27 January 2019

Published online: 22 February 2019

References

Ahmadi, A., \& Mirshojaee, S. B. (2016). Iranian English language teachers' assessment literacy: The case of public school and language institute teachers. Iranian EFL Journal, 12(2), 6-32. 
Atai, M. R., \& Mazlum, F. (2013). English language teaching curriculum in Iran: Planning and practice. The Curriculum Journal, 24(3), 389-411. Bachman, L. F. (1990). Fundamental considerations in language testing. Oxford: Oxford University Press.

Berry, R. (2011). Assessment reforms around the world. In R. Berry \& B. Adamson (Eds.), Assessment reform in education: Policy and practice (pp. 89-102). Dordrecht: Springer Netherlands.

Black, P., \& Wiliam, D. (1998). Assessment and classroom learning. Assessment in Education, 5(1), 7-74.

Black, P., \& Wiliam, D. (2018). Classroom assessment and pedagogy. Assessment in Education: Principles, Policy \& Practice, 25(1), 1-25.

Brindley, G. (2001). Language assessment and professional development. Experimenting with Uncertainty: Essays in Honour of Alan Davies, 11, 137-143

Brookhart, S. M. (2003). Developing measurement theory for classroom assessment purposes and uses. Educational Measurement: Issues and Practice, 22(4), 5-12.

Brookhart, S. M. (2011). Educational assessment knowledge and skills for teachers. Educational Measurement: Issues and Practice, 30(1), 3-12.

Brookhart, S. M. (2013). How to create and use rubrics for formative assessment and grading. Alexandria: Association for Supervision \& Curriculum Development.

Carless, D. (2009). Trust, distrust and their impact on assessment reform. Assessment \& Evaluation in Higher Education, 34(1), $79-89$.

Crusan, D., Plakans, L., \& Gebril, A. (2016). Writing assessment literacy: Surveying second language teachers' knowledge, beliefs, and practices. Assessing Writing, 28, 43-56.

Davies, A. (2008). Textbook trends in teaching language testing. Language Testing, 25(3), 327-347.

DeLuca, C., LaPointe-McEwan, D., \& Luhanga, U. (2016). Teacher assessment literacy: A review of international standards and measures. Educational Assessment, Evaluation and Accountability, 28(3), 251-272.

Foroozandeh, E., \& Forouzani, M. (2015). Developing school English materials for the new Iranian educational system. In C. Kennedy (Ed.), English language teaching in the Islamic Republic of Iran: Innovations, trends and challenges (pp. 59-73). London: British Council.

Fulcher, G. (2012). Assessment literacy for the language classroom. Language Assessment Quarterly, 9(2), 113-132.

Fullan, M. (2012). Change forces: Probing the depths of educational reform. London: Routledge.

Gebril, A. (2016). Educational assessment in Muslim countries: Values, policies, and practices. In G. T. L. Brown \& L. R. Harris (Eds.), Handbook of human and social conditions in assessment (pp. 420-435). New York: Routledge.

Gebril, A., \& Brown, G. T. L. (2014). The effect of high-stakes examination systems on teacher beliefs: Egyptian teachers' conceptions of assessment. Assessment in Education: Principles, Policy \& Practice, 21(1), 16-33.

Gudmundsdottir, S., \& Shulman, L. (1987). Pedagogical content knowledge in social studies. Scandinavian Journal of Educational Research, 31(2), 59-70.

Hall, W. A., Long, B., Bermbach, N., Jordan, S., \& Patterson, K. (2005). Qualitative teamwork issues and strategies: Coordination through mutual adjustment. Qualitative Health Research, 15(3), 394-410.

Hayati, A. M., \& Mashhadi, A. (2010). Language planning and language-in-education policy in Iran. Language Problems and Language Planning, 34(1), 24-42.

Inbar-Lourie, O. (2008). Constructing a language assessment knowledge base: A focus on language assessment courses. Lanquage Testing, 25(3), 385-402.

Inbar-Lourie, O. (2013). Guest editorial to the special issue on language assessment literacy. Language Testing, 30(3), 301-307.

Jin, Y. (2010). The place of language testing and assessment in the professional preparation of foreign language teachers in China. Language Testing, 27(4), 555-584.

Mertler, C. A. (2001). Designing scoring rubrics for your classroom. Practical Assessment, Research and Evaluation, 7(25), 1.

Ministry of Education (2010a). Fundamental Reform Document of Education (FRDE) in the Islamic Republic of Iran.. Tehran, Iran: Ministry of Education.

Ministry of Education (2010b). National curriculum document (NCD) of the Islamic Republic of Iran. Tehran, Iran: Ministry of Education.

Morrow, C. K. (2018). Communicative language testing. In J. I. Liontas (Ed.), The TESOL Encyclopedia of English Language Teaching (pp. 342-350). United States, NJ: Wiley.

O'Loughlin, K. (2013). Developing the assessment literacy of university proficiency test users. Lanquage Testing, 30(3), 363-380.

Ölmezer-Öztürk, E., \& Aydin, B. (2018). Toward measuring language teachers' assessment knowledge: Development and validation of Language Assessment Knowledge Scale (LAKS). Language Testing in Asia, 8(1), 20.

Paivandi, S. (2012). Education in the Islamic Republic of Iran and perspectives on democratic reforms. London: Legatum Institute.

Patton, M. Q. (2014). Qualitative evaluation and research methods:Integrating theory and practice. New York: SAGE Publication, Inc..

Phillipson, R. (2016). Native speakers in linguistic imperialism. The Journal of Critical Education Policy Studies, 14(3), 80-96.

Pill, J., \& Harding, L. (2013). Defining the language assessment literacy gap: Evidence from a parliamentary inquiry. Language Testing, 30(3), 381-402.

Plake, B. S., Impara, J. C., \& Fager, J. J. (1993). Assessment competencies of teachers: A national survey. Educational Measurement: Issues and Practice, 12(4), 10-12.

Razavipour, K., \& Rezagah, K. (2018). Language assessment in the new English curriculum in Iran: Managerial, institutional, and professional barriers. Language Testing in Asia, 8(1), 1-18.

Razavipour, K., Riazi, A., \& Rashidi, N. (2011). On the interaction of test washback and teacher assessment literacy: The case of Iranian EFL secondary school teachers. English Language Teaching, 4(1), 156.

Rea-Dickins, P. (2006). Currents and eddies in the discourse of assessment: A learning-focused interpretation. International Journal of Applied Linguistics, 16(2), 163-188.

Rea-Dickins, P. (2008). Classroom-based language assessment. In N. H. Hornberger (Ed.), Encyclopedia of language and education (pp. 2391-2405). Boston: Springer US.

Riazi, A. (2005). The four language stages in the history of Iran. In A. M. Y. Lin \& P. W. Martin (Eds.), Decolonization, globalization: Language-in-education policy and practice (pp. 98-114). Clevedon: Multilingual Matters.

Scarino, A. (2013). Language assessment literacy as self-awareness: Understanding the role of interpretation in assessment and in teacher learning. Language Testing, 30(3), 309-327.

Stiggins, R. J., Arter, J. A., Chappuis, J., \& Chappuis, S. (2006). Classroom assessment for learning: Doing it right-using it well. Princeton: Educational Testing Service. 
Taylor, L. (2013). Communicating the theory, practice and principles of language testing to test stakeholders: Some reflections. Language Testing, 30(3), 403-412.

The World Bank Group, International Development, Poverty, and Sustainability (2018). Retrieved from http://microdata.worldbank. org/index.php/citations/3606

Vogt, K., \& Tsagari, D. (2014). Assessment literacy of foreign language teachers: Findings of a European study. Language Assessment Quarterly, 11(4), 374-402.

Xu, Y., \& Brown, G. T. L. (2016). Teacher assessment literacy in practice: A reconceptualization. Teaching and Teacher Education, $58,149-162$.

Zolfaghari, F., \& Ahmadi, A. (2016). Assessment literacy components across subject matters. Cogent Education, 3(1), 1-16.

Submit your manuscript to a SpringerOpen ${ }^{\circ}$ journal and benefit from:

- Convenient online submission

Rigorous peer review

- Open access: articles freely available online

High visibility within the field

- Retaining the copyright to your article

Submit your next manuscript at $\boldsymbol{\nabla}$ springeropen.com 